\title{
Proceedings of the 2016 ISNR Conference: Keynotes, Invited, and Student Award Presentations
}

\author{
Selected Abstracts of Conference Presentations at the 2016 International Society for Neurofeedback and \\ Research (ISNR) 24th Conference, Orlando, Florida, USA
}

Citation: International Society for Neurofeedback and Research. (2016). Proceedings of the 2016 ISNR Conference: Keynotes, Invited, and Student Award Presentations. NeuroRegulation, 3(4), 162-169. http://dx.doi.org/10.15540/nr.3.4.162

Copyright: @ 2016. ISNR. This is an Open Access article distributed under the terms of the Creative Commons Attribution License (CC-BY).

\section{KEYNOTE PRESENTATIONS}

\section{Closed-Loop Control of Corticothalamic Circuits to Prevent Seizures with Light Jeanne Paz}

Neuroscience and Biomedical Science graduate programs at the University of California San Francisco, San Francisco, California, USA

Gladstone Institute of Neurological Disease, San Francisco, California, USA

Thalamocortical communication drives conscious sensory experience as well as sleep and epileptic seizures associated with synchronized brain rhythms and loss of consciousness. Treating seizure disorders requires knowledge of active network nodes as potential targets. Evidence suggests that the thalamus is the pacemaker for sustaining seizures, but an alternative argument is that seizures are inherited passively from cortex. To directly test for an active thalamic role, we used opsins to specifically drive or disrupt synchronous firing of thalamocortical neurons in acquired and genetic epilepsy models of rats and mice. Driving synchronized thalamic bursts evoked absence seizures or sleep spindles, while driving tonic firing desynchronized oscillations and abruptly terminated sleep and seizures, switching behavior from unconsciousness to exploration. These results resolve a long-standing controversy regarding the role of the thalamus in corticothalamic rhythms by demonstrating both the sufficiency of thalamus in generating thalamocortical rhythms and its necessity in maintaining these states. These results support development of therapies specifically targeting phasic thalamic activity.

\section{References}

Paz, J. T., Bryant, A. S., Peng, K., Fenno, L. E., Yizhar, O., Frankel, W. N., ... Huguenard, J. R. (2011). A new mode of corticothalamic transmission revealed in the Gria4(-/-) model of absence epilepsy. Nature Neuroscience, 14(9), 11671173. http://dx.doi.org/10.1038/nn.2896

Paz, J. T., Davidson, T. J., Frechette, E. S., Delord, B., Parada, I., Peng, K., ... Huguenard, J. R. (2013). Closed-loop optogenetic control of thalamus as a tool for interrupting seizures after cortical injury. Nature Neuroscience, 16(1), 6470. http://dx.doi.org/10.1038/nn.3269

Paz, J. T., \& Huguenard, J. R. (2015). Microcircuits and their interactions in epilepsy: is the focus out of focus? Nature Neuroscience, 18(3), 351-359. http://dx.doi.org/10.1038 Inn.3950

Paz, J. T., \& Huguenard, J. R. (2015). Optogenetics and epilepsy: Past, present and future. Epilepsy Currents, 15(1), 34-38. http://dx.doi.org/10.5698/1535-7597-15.1.34

Yizhar, O., Fenno, L. E., Prigge, M., Schneider, F., Davidson, T. J., O'Shea, D. J., ... Deisseroth, K. (2011). Neocortical excitation/inhibition balance in information processing and social dysfunction. Nature, 477(7363), 171-178. http://dx.doi.org/10.1038/nature 10360

\section{Self-Organized Criticality as a Theoretical Framework for Neurofeedback Tomas Ros \\ Department of Fundamental Neurosciences, University of Geneva, Geneva, Switzerland}

Despite a rise in empirical evidence attesting to its benefits, a unifying theoretical basis is still lacking on the manner in which neurofeedback (NFB) is able to achieve clinical outcomes. Starting with mechanisms of neural synchronization, it is argued that hyper- and hyposynchronous oscillations reflect diametrically opposite states within a dynamical systems framework. Utilizing Hebbian as well as homeostatic models of brain plasticity, the effects of NFB are examined in several brain disorders including attention-deficit/hyperactivity (ADHD) and posttraumatic stress disorder (PTSD). Importantly, brain oscillations demonstrate fluctuations over extended spatial and temporal scales, manifesting as scale-free EEG and fMRI signals. Here, we report novel evidence that NFB re-tunes pathological oscillations toward normal levels of synchronization and temporal complexity, consistent with mechanisms of self-organized criticality (SOC). 


\section{References}

Kluetsch, R. C., Ros, T., Théberge, J., Frewen, P. A., Calhoun, V. D., Schmahl, C., ... Lanius, R. A. (2014). Plastic modulation of PTSD resting-state networks and subjective wellbeing by EEG neurofeedback. Acta Psychiatrica Scandinavica, 130(2), 123-136. http://dx.doi.org/10.1111/acps.12229

Ros, T., Baars, B. J., Lanius, R. A., \& Vuilleumier, P. (2014). Tuning pathological brain oscillations with neurofeedback: a systems neuroscience framework. Frontiers in Human Neuroscience, $\quad 8, \quad 1008 . \quad$ http://dx.doi.org/10.3389 /fnhum.2014.01008

Ros, T., Frewen, P., Theberge, J., Kluetsch, R., Mueller, A., Candrian, G., ... Lanius, R. (2015). Neurofeedback tunes long-range temporal correlations in spontaneous brain activity. Arxiv Papers, 15120.9133, 1-19. https://arxiv.org/ftp /arxiv/papers/1512/1512.09133.pdf

\section{Genes, Brains, and Neuroplasticity in Developmental Dyslexia \\ Karen Waldie \\ University of Auckland, Auckland, New Zealand}

Dyslexia is a developmental disorder characterized by reading and phonological difficulties, yet important questions remain regarding its underlying neural correlates. In this presentation, I will take the audience through the most accepted research into dyslexia and other neurodevelopmental disorders. We will cover diagnoses, cognitive research, longitudinal research, and neurological findings. In our most recent functional magnetic resonance imaging (fMRI) study, we conducted a multivariate Partial Least Squares (PLS) analysis of the neural networks used by dyslexics while performing a wordrhyming task. Although the overall reading network was largely similar in dyslexics and typical readers, it did not correlate with behavior in the same way in the two groups. In particular, there was a positive association between reading performance and both right superior temporal gyrus and bilateral insula activation in dyslexic readers but a negative correlation in typical readers. Together with differences in lateralization unique to dyslexics, this suggests that the combination of poor reading performance with high insula activity and atypical laterality is a consistent marker of dyslexia. These findings emphasize the importance of understanding right-hemisphere activation in dyslexia and provide promising directions for the remediation of reading disorders.

\section{References}

Moreau, D., Kirk, I. J., \& Waldie, K. E. (2016). Seven pervasive statistical flaws in cognitive training interventions. Frontiers in Human Neuroscience, 10, 153. http://dx.doi.org/10.3389 /fnhum.2016.00153
Moreau, D., \& Waldie, K. E. (2016). Developmental learning disorders: From generic interventions to individualized remediation. Frontiers in Psychology, 6, 2053. http://dx.doi.org/10.3389/fpsyg.2015.02053

Waldie, K. E., Haigh, C. E., Badzakova-Trajkov, G., Buckley, J., \& Kirk, I. J. (2013). Reading the wrong way with the right hemisphere. Brain Sciences, 3(3), 1060-1075. http://dx.doi.org/10.3390/brainsci3031060

Wilson, A. J., Andrewes, S. G., Struthers, H., Rowe, V. M., Bogdanovic, R., \& Waldie, K. E. (2015). Dyscalculia and dyslexia in adults: Cognitive bases of comorbidity. Learning and Individual Differences, 37, 118-132. http://dx.doi.org /10.1016/j.lindif.2014.11.017

\section{INVITED PRESENTATIONS}

\author{
Reward Deficiency Solution System: \\ Neurogenetic and Neuroimaging Translational \\ Neural Regulation Having Clinical Relevance \\ Kenneth Blum \\ University of Texas, Austin, Texas, USA \\ Keck School of Medicine, University of Southern California, Los \\ Angeles, California, USA \\ LaVita RDS, Lehi, Utah, USA \\ Igene, LLC, Columbia, Maryland, USA
}

Following the first association between the dopamine D2 receptor gene polymorphism and severe alcoholism, there has been an explosion of research reports in the psychiatric and behavioral addiction literature and neurogenetics. Along with Functional Genome Convergence, the multiplecandidate gene approach still has merit and is considered by many as the most prudent approach. Since 1996, our laboratory has coined the umbrella term Reward Deficiency Syndrome (RDS) to explain the common neurochemical and genetic mechanisms involved with both substance and nonsubstance, addictive behaviors. Importantly, the proposal is that the real phenotype is RDS and impairments in the brain's reward cascade, either genetically or environmentally (epigenetically) induced, influence both substance and nonsubstance, addictive behaviors. Understanding shared common mechanisms will ultimately lead to better diagnosis, treatment, and prevention of relapse. Our neurogenetic and neuroimaging data is dedicated to all the people who have lost loved ones in substance abuse and "reward deficiency syndrome" related tragedies. Why are we failing at reducing the incidence of 'Bad Behaviors'? Are we aiming at the wrong treatment targets for behavioral disorders? Can we couple NFB with Pro-Dopamine regulation as a paradigm shift and call it "Reward Deficiency Solution System" providing evidence for its adoption? 


\section{References}

Blum, K., Febo, M., Badgaiyan, R. D., Demetrovics, Z., Simpatico, T., Fahlke, C., ... Gold, M. S. (2016). Common neurogenetic diagnosis and meso-limbic manipulation of hypodopaminergic function in Reward Deficiency Syndrome (RDS): Changing the recovery landscape. Current Neuropharmacology. Advanced online publication. http://dx.doi.org/10.2174 /1570159X13666160512150918

Blum, K., Febo, M., McLaughlin, T., Cronjé, F. J., Han, D., Gold, M. S. (2014). Hatching the behavioral addiction egg: Reward Deficiency Solution System (RDSS) ${ }^{\mathrm{TM}}$ as a function of dopaminergic neurogenetics and brain functional connectivity linking all addictions under a common rubric. Journal of Behavioral Addictions, 3(3), 149-156. http://dx.doi.org /10.1556/JBA.3.2014.019

Blum, K., Febo, M., Smith, D. E., Roy, A. K., Demetrovics, Z. Cronjé, F. J., ... Gold, M. S. (2015). Neurogenetic and epigenetic correlates of adolescent predisposition to and risk for addictive behaviors as a function of prefrontal cortex dysregulation. Journal of Child and Adolescent Psychopharmacology, 25(4), 286-292. http://dx.doi.org /10.1089/cap.2014.0146

Blum, K., Liu, Y., Wang, W., Wang, Y., Zhang, Y., Oscar-Berman, M., ... Gold, M. S. (2015). rsfMRI effects of KB220Z ${ }^{\mathrm{TM}}$ on neural pathways in reward circuitry of abstinent genotyped heroin addicts. Postgraduate Medicine, 127(2), 232-241. http://dx.doi.org/10.1080/00325481.2015.994879

Blum, K., Oscar-Berman, M., Badgaiyan, R. D., Palomo, T., \& Gold, M. S. (2014). Hypothesizing dopaminergic genetic antecedents in schizophrenia and substance seeking behavior. Medical Hypotheses, 82(5), 606-614. http://dx.doi.org/10.1016/j.mehy.2014.02.019

Blum, K., Thanos, P. K., \& Gold, M. S. (2014). Dopamine and glucose, obesity, and reward deficiency syndrome. Frontiers in Psychology, 5, 919. http://dx.doi.org/10.3389 /fpsyg.2014.00919

Downs, B. W., Oscar-Berman, M., Waite, R. L., Madigan, M. A. Giordano, J., Beley, T., ... Blum, K. (2013). Have we hatched the addiction egg: Reward Deficiency Syndrome Solution System ${ }^{\mathrm{TM}}$. Journal of Genetic Syndromes and Gene Therapy, 4(136), 14318. http://dx.doi.org/10.4172/2157-7412.1000136

Miller, D. K., Bowirrat, A., Manka, M., Miller, M., Stokes, S., Manka, D., ... Blum, K. (2010). Acute intravenous synaptamine complex variant KB220 ${ }^{\mathrm{TM}}$ "normalizes" neurological dysregulation in patients during protracted abstinence from alcohol and opiates as observed using quantitative electroencephalographic and genetic analysis for reward polymorphisms: part 1, pilot study with 2 case reports. Postgraduate Medicine, 122(6), 188-213. http://dx.doi.org /10.3810/pgm.2010.11.2236

\section{Brain Connectivity and Neural Dynamics - Principles and Applications \\ Iman Mohammad-Rezazadeh}

Department of Psychiatry and Biobehavioral Sciences, Semel Institute for Neuroscience and Human Behavior, David Geffen School of Medicine, University of California, Los Angeles, Los Angeles, California, USA

Recently, many neuroimaging studies have shown that individuals with autism spectrum disorder (ASD) exhibit different brain connectivity patterns compared to typically developing controls. While the findings of many studies largely based on functional magnetic resonance imaging (fMRI) are often summarized as local hyperconnectivity and longrange hypoconnectivity in ASD, a number of current connectivity studies using cortical recording methods such as electroencephalography (EEG) and magnetoencephalography (MEG) do not match this simple explanation. There are many reasons behind this controversy in findings, including (1) the task during EEG recording, (2) the age of patients examined, (3) the anatomical region(s) examined, (4) the time intervals and frequency band(s) in which connectivity was analyzed, and (5) the way the connectivity between brain regions measured-the connectivity estimator.

\section{References}

Coben, R., \& Mohammad-Rezazadeh, I. (2015). Neural connectivity in epilepsy as measured by Granger causality. Frontiers in Human Neuroscience. 9, 194. http://dx.doi.org/10.3389/fnhum.2015.00194

Coben, R., Mohammad-Rezazadeh, I., \& Cannon, R. L. (2014). Using quantitative and analytic EEG methods in the understanding of connectivity in autism spectrum disorders: A theory of mixed over- and under-connectivity. Frontiers in Human Neuroscience. 8, 45. http://dx.doi.org/10.3389 /fnhum.2014.00045

Mohammad-Rezazadeh, I., Frohlich, J., Loo, S. K. \& Jeste, S. S. (2016). Brain connectivity in autism spectrum disorder. Current Opinion in Neurology, 29(2), 137-147. http://dx.doi.org/10.1097/WCO.0000000000000301

\section{Eating and the Brain: Using EEG to Understand Eating Behavior and Weight Gain \\ Proneness \\ Samantha Winter \\ Drexel University, Philadelphia, Pennsylvania, USA}

Battling obesity and obesity-related diseases is now a $\$ 300$ billion industry. Understanding who is susceptible, identifying underlying causes and developing targeted interventions for obesity is now more important than ever. A subset of research outside of the eating field is beginning to use electroencephalography (EEG) in order to provide real-time feedback on brain functioning in attempts to modulate behavior. We provide early evidence for the potential utility of EEG in the conceptualization and, ultimately, treatment of obesity. Our major findings have linked specific patterns asymmetrical activation in the frontal lobe to dietary restraint and susceptibility to the food environment, respectively. Furthermore, frontal asymmetry in the same sample predicted weight gain 1 year later. Together, our findings demonstrate the efficacy of EEG and potential for neurofeedback as a preventative treatment for obesity. 


\section{References}

Ely, A. V., Winter, S. R., \& Lowe, M. R. (2013). The generation and inhibition of hedonically-driven food intake: Behavioral and neurophysiological determinants in healthy weight individuals. Physiology \& Behavior, 121, 25-34. http://dx.doi.org/10.1016/j.physbeh.2013.03.026

Lowe, M. R., Feig, E. H., Winter, S. R., \& Stice, E. (2015). Shortterm variability in body weight predicts long-term weight gain. The American Journal of Clinical Nutrition, 102(5), 995-999. http://dx.doi.org/10.3945/ajcn.115.115402

Winter, S. R., Feig, E. H., Erickson, B., Berkowitz, S., Kounios, J., Lowe, M. R. (2016). The relation of hedonic hunger and restrained eating to lateralized frontal activation. Physiology \& Behavior, 163, 64-69. http://dx.doi.org/10.1016 /j.physbeh.2016.04.050

\section{STUDENT AWARD WINNERS - PLENARY PRESENTATIONS}

\section{Riding the Wave to Recovery: sLORETA qEEG in Sport-Related Concussion \\ David Ims \\ Chesapeake Neurology Associates, Prince Frederick, Maryland, USA}

Introduction/Support. Concussion is a complex pathophysiologic process affecting the brain, induced by biomechanical forces (McCrory et al., 2013). Trauma-induced diffuse axonal injury disrupts neuronal membrane electrolyte equilibrium and increases the metabolic load on affected neurons, compromising neuronal restoration to healthy functioning. Electroencephalography (EEG) measures differences in neuron-generated electrical potentials, and concussion results in measurable EEG abnormalities (Rapp et al., 2015). Threedimensional current source density analysis utilizing standardized low resolution electromagnetic tomography (sLORETA) integrated with Quantitative EEG (qEEG) normative database techniques allows for high-precision localization of cerebral physiology. The advent of concussion management protocols such as the XLNTbrain Sport concussion management program utilizing internet-based computerized neurocognitive testing and symptom tracking allows for simplified management of concussion.

Hypothesis/Justification. As the majority of CT and MRI studies are normal in concussed individuals (Tator, 2013), qEEG warrants further investigation as an objective concussion assessment measure. It then follows that qEEG analysis can be integrated into a comprehensive symptom and cognitive performance based program to further our understanding of the concussion recovery process.
We hypothesize that qEEG, particularly sLORETA analysis parallels concussion injury recovery.

Methods. The sport arena provides a semicontrolled environment where the effects of brain trauma can be observed, presenting a unique opportunity to study the natural course of concussion injury and recovery in athletes by standard concussion management programs integrated with qEEG. The XLNTbrain Sport concussion management program monitors changes in symptoms and computerized neurocognitive measures. Comparison of neurocognitive measures postinjury, and after return-to-baseline demonstrate change in cognitive performance and symptoms over the course of the recovery from injury. qEEG data is acquired postconcussion and when cognitive measures return-to-baseline. qEEG and sLORETA data at these time points are compared. We examine the relationship between qEEG metrics and neurocognitive measures in the recovery process.

Results. Two patterns of qEEG changes emerge in this analysis: (1) regional increase in delta/theta activity, particularly in the frontal and temporal lobes, and (2) regional and often generalized increase in beta/gamma activity. Resolution of the increased slow wave activity parallels symptom and cognitive performance recovery from concussion injury, while changes in gamma activity are more often persistent after clinical resolution.

Conclusion. This study suggests that changes in cerebral electrophysiology persist beyond current standards of determination of clinical recovery. We hypothesize the generalized increase in gamma activity represents cortical-cortical communication in the wake of deafferentation from deeper thalamic and brainstem structures due to axonal injury, while increased slow wave activity depicts regional cortical dysfunction due to direct trauma. Our findings suggest persistent pathophysiologic changes that may play a significant role in clinical return to play decision making and neurotheraputic protocol design. We propose that qEEG analysis should be included in baseline assessments of athletes and other individuals prone to concussion injury so direct within-subject comparisons can be made. Further research is needed to more definitively characterize the relationship between qEEG and recovery from injury.

\section{References}

McCrory, P., Meeuwisse, W. H., Aubry, M., Cantu, B., Dvořák, J., Echemendia, R. J., ... Turner, M. (2013). Consensus statement on concussion in sport: The 4th International 
Conference on Concussion in Sport held in Zurich, November 2012. British Journal of Sports Medicine, 47(5), 250-258. http://dx.doi.org/10.1136/bjsports.2013.092313

Rapp, P. E., Keyser, D. O., Albano, A., Hernandez, R., Gibson, D. B., Zambon, R. A., ... Nichols, A. S. (2015). Traumatic brain injury detection using electrophysiological methods. Frontiers in Human Neuroscience, 9, 11. http://dx.doi.org/10.3389 /fnhum.2015.00011

Tator, C. H. (2013). Concussions and their consequences: Current diagnosis, management and prevention. Canadian Medical Association Journal, 185(11), 975-979. http://dx.doi.org/10.1503/cmaj.120039

\section{Finding the Beat: Simultaneously-Recorded Cortical and Subcortical Steady-State Responses to Missing Pulse Rhythms Charles Wasserman, Jung Nyo Kim, Edward Large, and Erika Skoe \\ University of Connecticut, Storrs, Connecticut, USA}

Many rhythm perception experiments employ simple isochronous rhythms, in which synchronous neural or behavioral responses are observed. However, responses at the stimulus frequency do not allow one to distinguish whether synchrony occurs as a response to a common input or as the result of an emergent population oscillation that entrains at a particular frequency. Stimulus complexity can be increased by manipulating the number of events that occur anti-phase $\left(180^{\circ}\right)$ versus in-phase $\left(0^{\circ}\right)$ with the basic rhythmic cycle. It is possible to create a rhythm with no spectral energy at the pulse frequency, however, by manipulating the number of events that occur anti-phase $\left(180^{\circ}\right)$ versus in-phase $\left(0^{\circ}\right)$ with the basic rhythmic cycle. Dynamical analysis predicts neural oscillation will emerge at such a "missing" pulse frequency, where a complex rhythm contains no spectral energy. Previous studies have shown that subjects are able to tap along to complex rhythms that contain no spectral power at the missing pulse frequency-a finding that supports the prediction. This study aimed to investigate whether the auditory sensorimotor system, as measured by 32-channel cortical EEG, would entrain to a complex rhythm at the pulse frequency of a complex rhythm even when the complex rhythm has contained no spectral power at that pulse frequency. The experiment utilized four different rhythms of varying complexity ( 1 simple, 2 complex, and 1 random) created from 150-ms tones with a $200-\mathrm{Hz}$ fundamental frequency (F0). For the simple rhythm, Fast Fourier Transform (FFT) of the Hilbert envelope showed energy at the repetition (pulse) frequency $(2 \mathrm{~Hz})$ for the simple rhythm and its harmonics $(4 \mathrm{~Hz})$. For the complex rhythm there was no spectral energy at the missing pulse frequency $(2 \mathrm{~Hz})$ for the complex rhythms. EEG responses to these stimuli were recorded to look for the neural oscillations at the missing pulse frequency predicted by dynamical analysis. FFT of the cortical steady-state response showed energy at the "missing" pulse frequency $(2 \mathrm{~Hz})$ for both the simple and complex rhythms. These data support the theory that this rhythmic synchrony occurs as the result of an emergent population oscillation that entrains at this particular frequency. Additional analyses examined whether the Frequency Following Response (FFR) to the $200 \mathrm{~Hz} \mathrm{F0}$ is modulated by whether the stimuli are in-phase versus anti-phase with the entrained cortical rhythm.

\section{References}

Drullman, R., Festen, J. M., \& Plomp, R. (1994). Effect of reducing slow temporal modulations on speech reception. The Journal of the Acoustical Society of America, 95(5 Pt 1), 2670-2680. http://dx.doi.org/10.1121/1.409836

Geringer, J. M., Madsen, C. K., MacLeod, R. B., \& Droe, K. (2006). The effect of articulation style on perception of modulated tempo. Journal of Research in Music Education, 54, 321-336. http://dx.doi.org/10.1177/002242940605400405

Hackett, T. A. (2011). Information flow in the auditory cortical network. Hearing Research, 271(1-2), 133-146. http://doi.org/10.1016/j.heares.2010.01.011

Irino, T., \& Patterson, R. D. (1996). Temporal asymmetry in the auditory system. The Journal of the Acoustical Society of America, 99(4), 2316-2331. http://dx.doi.org/10.1121 $/ 1.415419$

Iverson, P., \& Krumhansl, C. L. (1993). Isolating the dynamic attributes of musical timbre. The Journal of the Acoustical Society of America, 94(5), 2595-2603. http://dx.doi.org $/ 10.1121 / 1.407371$

Kuwada, S., Bishop, B. B., \& Kim, D. O. (2014). Azimuth and envelope coding in the inferior colliculus of the unanesthetized rabbit: Effect of reverberation and distance. Journal of Neurophysiology, 112(6), 1340-1355. http://dx.doi.org/10.1152/jn.00826.2013

Large, E. W. (2010). Neurodynamics of music. In M. R. Jones, R. R. Fay, \& A. N. Popper (Eds.), Springer Handbook of Auditory Research Volume 36: Music Perception (Vol. 36, pp. 201231). Springer Science+Business Media, LLC. Retrieved from http://link.springer.com/10.1007/978-1-4419-6114-3_7

Prendergast, G., Johnson, S. R., \& Green, G. G. R. (2010). Temporal dynamics of sinusoidal and non-sinusoidal amplitude modulation. European Journal of Neuroscience, 32(9), 1599-1607. http://dx.doi.org/10.1111/j.14609568.2010.07423.x

Skoe, E., \& Kraus, N. (2011). Auditory brainstem response to complex sounds: A tutorial. Ear Hear, 31(3), 302-324. http://dx.doi.org/10.1097/AUD.0b013e3181cdb272 


\section{STUDENT AWARD WINNERS - POSTER PRESENTATIONS}

\author{
Differences in Theta Power Between Experts \\ and Novices in the Preparation Phase of Golf \\ Putting \\ Yen-Yo Tsai ${ }^{1}$, Kuo-Pin Wang ${ }^{1}$, Tai-Ting Chen ${ }^{1}$, Kuan- \\ Fu Chen ${ }^{1}$, Cheng-En Chiang ${ }^{1}$, Chung-Ju Huang ${ }^{2}$, and \\ Tsung-Min Hung \\ ${ }^{1}$ National Taiwan Normal University, Taiwan \\ ${ }^{2}$ University of Taipei, Taiwan
}

Purpose. The theta activity is an indicator of action monitoring, cognitive control, and reflecting an engagement of volitional attentional control. Previous electroencephalographic (EEG) studies have demonstrated higher Fz theta power in experts than novices in the golf putting task. This study extended this knowledge base by including a measure of self-report attention engagement score to supplement the EEG measurement.

Methods. The 13 skilled golfers (mean handicap $=$ $4.4, S D= \pm 2.2$ ) and 16 novices were recruited, and all participants performed 60 putts in 6 separate blocks on artificial golf green while EEG data and self-report attention engagement score as measured by from visual analogue scale were obtained.

Results. The 2 (Group: expert, novice) $\times 6$ (Electrode: Fz, Cz, Pz, Oz, T3, T4) ANOVA revealed a significant interaction effect between groups and electrodes. Post hoc simple main effect analysis indicated that the expert's theta power at Fz, Pz, and T3 was higher than that of novice's, whereas theta power at T4 was lower than that of novice's. On the other hand, novices revealed higher attention score than experts.

Discussion. The finding of this study is consistent with previous EEG and behavioral studies and also supports previous research that experts felt effortless and involved in effective allocation of the neural resources associated with the attention network for golf putting task. The results also show that expert has better attention engagement allocation (higher $\mathrm{Fz}$ theta power), better motor control (higher $\mathrm{Pz}$ theta power), and effective retrieval motor memory encoding (higher T3 and lower T4 theta power) during the preparation phase.

\section{References}

Baumeister, J., Reinecke, K., Liesen, H., \& Weiss, M. (2008). Cortical activity of skilled performance in a complex sports related motor task. European Journal of Applied Physiology, 104(4), 625-631. http://dx.doi.org/10.1007/s00421-008-0811$x$

Guderian, S., Schott, B. H., Richardson-Klavehn, A., \& Düzel, E. (2009). Medial temporal theta state before an event predicts episodic encoding success in humans. Proceedings of the National Academy of Sciences of the United States of America, 106(13), 5365-5370. http://dx.doi.org/10.1073 /pnas.0900289106

Kao, S.-C., Huang, C.-J., \& Hung, T.-M. (2013). Frontal midline theta is a specific indicator of optimal attentional engagement during skilled putting performance. Journal of Sport \& Exercise Psychology, 35(5) 470-478.

Hemispheric Difference on EEG 8-13 Hz Between Skilled Golfers and Novices During the Aiming Period of Golf Putting Cheng-En Chiang ${ }^{1}$, Kuo-Pin Wang ${ }^{1}$, Tai-Ting Chen ${ }^{1}$, Kuan-Fu Chen ${ }^{1}$, Yen-Yo Tsai', Chung-Ju Huang ${ }^{2}$, and Tsung-Min Hung ${ }^{1}$

${ }^{1}$ National Taiwan Normal University, Taiwan

${ }^{2}$ University of Taipei, Taiwan

Purpose. Previous studies focused on the difference of a single frequency band between experts and novices in golf putting task. Higher cognitive functions such as perception, spatial cognition, and attention show some degree of hemispheric specialization (Hellige, 1993; Davidson \& Hugdahl, 1995). Specifically, increased alpha power of the left hemisphere has been related with visuospatial and motor coordination, relative to that observed in the right. However, whether this hemispheric asymmetry can be observed between skilled golfers and novices during an aiming period of golf putting remains unknown. Therefore, the purpose of this study was to compare hemispheric differences on the 8-13 Hz between skilled golfers and novices during an aiming period of golf putting.

Methods. The 13 skilled golfers (mean handicap $=$ $4.4, S D= \pm 2.2$ ) and 18 novices volunteered. All participants performed 60 putts in 6 separate blocks in golf putting task. EEG from the left and right frontal (F3, F4), central (C3, C4), temporal (T3, T4), parietal $(\mathrm{P} 3, \mathrm{P} 4)$, and occipital $(\mathrm{O} 1, \mathrm{O} 2)$ sites were recorded and alpha $(8-13 \mathrm{~Hz})$ from the last 2 seconds prior to putting were analyzed.

Results. The 2 (Group: expert, novice) x 5 (Regions: frontal, central, temporal, parietal, and occipital) $\times 2$ (Hemisphere: left, right) ANOVA revealed a significant interaction effect between groups and hemisphere. Post hoc simple main 
effect analysis indicated that the alpha power from both hemispheres are higher in experts than that of novices. This result suggests that experts exhibit less cortical effort to process visuospatial and motor coordination during the aiming period of golf putting, which is according with neural efficiency hypothesis.

Conclusion. The finding of this study is consistent with previous study that showed a superior engagement of visuospatial resources for effective performance in expert than novices during golf putting task. On the other hand, novices would cost more cortical effort to process the information required to successfully aim the golf on the target. Therefore, the present results lend support to suggest that reduced activation in the whole brain area is a key to producing better performance in skilled athletes (Baumeister, Reinecke, Liesen, \& Weiss, 2008).

\section{References}

Baumeister, J., Reinecke, K., Liesen, H., \& Weiss, M. (2008). Cortical activity of skilled performance in a complex sports related motor task. European Journal of Applied Physiology, 104(4), 625-631. http://dx.doi.org/10.1007/s00421-008-0811-

Davidson, R. J., \& Hugdahl, K. (1995). Brain Asymmetry. Cambridge, MA: MIT Press.

Hellige, J. B. (1993). Hemispheric Asymmetry: What's Right and What's Left. Cambridge, MA: Harvard University Press.

\section{Changes in Neural Resting State Cortical}

Activity During Putting Skill Learning

Tai-Ting Chen ${ }^{1}$, Chen Shen ${ }^{1}$, Kung-Fu Chen ${ }^{1}$, Kuo-Pin Wang $^{1}$, Yen-Yo Tsai ${ }^{1}$, Cheng-En Chiang ${ }^{1}$, Chung-Ju Huang $^{2}$, and Tsung-Min Hung ${ }^{1}$

${ }^{1}$ National Taiwan Normal University, Taiwan

${ }^{2}$ University of Taipei, Taiwan

Spontaneous activation in the resting state of the brain can be affected by learning. Motor skill learning could be rapid during the very early stages of learning, which is accompanied by changes in the strength of connections within frontal, central, parietal, and occipital areas. Moreover, it requires intense top-down attention to perceptual-motor skills. However, no study has investigated changes in the resting state cortical activity during the verbalcognitive stage of skill learning. Therefore, the purpose of the present study was to examine changes in cortical activity associated with novice golf putting learning in three different learning stages [baseline, improved by $50 \%(150 \%)$, and improved by $80 \%(180 \%)]$. We hypothesized that sustained attention (frontal midline theta power) is the most critical factor for putting skill learning. Fourteen participants, right-handed, between 18 and 22 years of age, were recruited and practiced golf putts in one session of 60 putts two or three times a week. Participants would move to the next stage if he or she practiced at least six times and hit the targeting score in the last three consecutive times. EEG activities were recorded for 1-min, eyes-open in the resting state at baseline, $150 \%$ and $180 \%$ scores during golf putting practice. EEG power at $\mathrm{Fz}, \mathrm{Cz}$, $\mathrm{Pz}$, and $\mathrm{Oz}$ was computed for the theta $(4-8 \mathrm{~Hz})$, alpha $(8-13 \mathrm{~Hz})$, and beta $(15-30 \mathrm{~Hz})$ bandwidths. Three $3 \times 4$ (stage $\times$ electrode) ANOVAs with repeated measures were conducted separately for theta, alpha, and beta power. The results demonstrate that only theta power at Fz significantly increased during putting skill learning, which suggests that top-down sustained attention plays an important role through the verbal-cognitive stage of golf putting learning. Perceptual-motor information processing seems to play a less important role in golf putting learning.

\section{References}

Kao, S.-C., Huang, C.-J., \& Hung, T.-M. (2013). Frontal midline theta is a specific indicator of optimal attentional engagement during skilled putting performance. Journal of Sport \& Exercise Psychology, 35(5), 470-478. http://dx.doi.org /10.1123/jsep.35.5.470

Kiefer, A. W., Gualberto Cremades, J., \& Myer, G. D. (2014). Train the brain: Novel electroencephalography data indicate links between motor learning and brain adaptations. Journal of Novel Physiotherapies, 4(2), $198 . \quad$ http://dx.doi.org /10.4172/2165-7025.1000198

Ma, L., Narayana, S., Robin, D. A., Fox, P. T., \& Xiong, J. (2011). Changes occur in resting state network of motor system during 4 weeks of motor skill learning. Neurolmage, 58(1) 226-233. http://dx.doi.org/10.1016/j.neuroimage.2011.06.014

Neurofeedback Treatment in Response to Veterans Arrested for Domestic Violence with History of Traumatic Brain Injury: A Pilot Study

Linda Larson Spagon ${ }^{1}$, Karen Neil ${ }^{1}$, and Myron Thurber ${ }^{2}$

${ }^{1}$ Idaho State University, Pocatello, Idaho, USA

${ }^{2}$ Neurotherapy Northwest, Spokane Valley, Washington, USA

Background and Description. Domestic violence, also referred to as intimate partner violence (IPV) is recognized as a complex, significant public and social health problem. The intersection of IPV and combat-related issues, such as TBI among returning veterans, is the focus of this study. Veterans who have experienced injuries to the head and neck during deployment to Iraq and Afghanistan are estimated at $30 \%$ of over 2.5 million, with $70 \%$ to $80 \%$ considered mTBI. Veterans are arrested for 
domestic violence in significant numbers with the link to TBI established in the current literature. Across the U.S., the judicial response to domestic violence (DV) as a treatment approach consists of mandated, cognitive-based group, one-size-fits all programs which are based on established state standards. The current research on the outcomes of these programs indicate little to no effect on reducing DV recidivism. There is a need to consider new and innovative approaches for addressing DV offender treatment and neurofeedback treatments for TBI has shown positive effects.

Methods. The study design will be a randomized clinical trial pilot. The purpose of the study is to investigate the addition of neurofeedback as treatment modalities for veterans mandated to a domestic violence treatment program, presenting with a history of TBI. Research hypotheses will include statements of prediction related to pre- and postmeasurement of brain map outcomes, heart rate variability, anger and aggression with neurofeedback treatment as an additive component to mandated state-approved domestic violence treatment (control). The population will include veterans arrested for domestic violence and mandated to a state-approved treatment program through a single Veteran's Judicial Court in the northwest. The sample ( $n=20 ; 10$ assigned to each group) will consist of veterans arrested for domestic violence with a history of head injury noted on initial intake into a single state-approved offender intervention program. Veterans will be randomly placed in either the control group or the treatment group. Measures will include pre- and post-qEEG brain map, comparing LORETA progress reports of deviations from normal, and pre- and post-heart rate variability, as well as variables of anger and aggression. Instruments with strong psychometric properties will be used to measure anger and aggression pre- and posttreatment in all groups. SPSS will be used for analysis of data collected.

Results. Outcomes to be measured in terms of significance pre- to posttreatment in both groups.

Summary - Justification. TBI is a major issue in veterans returning home from combat and is a risk factor for IPV. Innovative treatments such as Neurofeedback will provide the judicial system with options for the veteran population with a history of $\mathrm{TBI}$. There is a dearth in the literature in regards to these treatment modalities in response to domestic violence. Research in this area will provide further evidence around the usefulness of other treatment options in addressing IPV in this population.

\section{References}

Breiding, M. J., Chen, J., \& Black, M. C. (2014). Intimate Partner Violence in the United States-2010. Atlanta, GA: National Center for Injury Prevention and Control, Centers for Disease Control and Prevention. Retrieved from http://www.cdc.gov /violenceprevention/pdf/cdc_nisvs_ipv_report_2013_v17_sing le_a.pdf

Camp̄̄ell, M., Neil, J. A., Jaffe, P. G., \& Kelly, T. (2010). Engaging abusive men seeking community intervention: A critical research and practice priority. Journal of Family Violence, 25(4), 413-422. http://dx.doi.org/10.1007/s10896$010-9302-z$

Corvo, K., \& Dutton, D. (2015). Neurotransmitter and Neurochemical factors in domestic violence perpetration: Implications for theory development. Partner Abuse, 6(3), 351-363. http://dx.doi.org/10.1891/1946-6560.6.3.351

Farrer, T. J., Frost, R. B., \& Hedges, D. W. (2012). Prevalence of traumatic brain injury in intimate partner violence offenders compared to the general population: A meta-analysis. Trauma, Violence, \& Abuse, 13(2), 77-82. http://dx.doi.org $/ 10.1177 / 1524838012440338$

García-Moreno, C., Jansen, H., Watts, C., Ellsberg, M. \& Heise, L. (2005). WHO multi-country study on women's health and domestic violence against women. Geneva, Switzerland: World Health Organization

Howard, C. J. (2012). Neurobiological correlates of partner abusive men: Equifinality in perpetrators of intimate partner violence. Psychological Trauma: Theory, Research, Practice, and Policy, 4(3), 330-337. http://dx.doi.org/10.1037 la0024229

Kwako, L. E., Glass, N., Campbell, J., Melvin, K. C., Barr, T., \& Gill, J. M. (2011). Traumatic brain injury in intimate partner violence: a critical review of outcomes and mechanisms. Trauma, Violence, \& Abuse, 12(3), 115-126. http://dx.doi.org $/ 10.1177 / 1524838011404251$

May, G., Benson, R., Balon, R., \& Boutros, N. (2013). Neurofeedback and traumatic brain injury: A literature review. Annals of Clinical Psychiatry, 25(4), 289-296.

Miller, T. R., Cohen., M. A., \& Wiersema, B. (1996). Victim costs and consequences: $A$ new look. Washington, DC: Nation Institute of Justice.

Pinto, L. A., Sullivan, E. L., Rosenbaum, A., Wyngarden, N. Umhau, J. C., Miller, M. W., \& Taft, C. T. (2010). Biological correlates of intimate partner violence perpetration Aggression and Violent Behavior, 15(5), 387-398. http://dx.doi.org/10.1016/j.avb.2010.07.001

Thompson, M., \& Thompson, L. (2015). The Neurofeedback Book (2nd ed.). Toronto, Canada: Biofeedback Institute of Toronto.

Tinney, G., \& Gerlock, A. A. (2014). Intimate partner violence, military personnel, veterans, and their families. Family Court Review, 52(3), 400-416. http://dx.doi.org/10.1111/fcre.12100

Walling, S. M., Meehan, J. C., Marshall, A. D., HoltzworthMunroe, A., \& Taft, C. T. (2012). The relationship of intimate partner aggression to head injury, executive functioning, and intelligence. Journal of Marital and Family Therapy, 38(3), 471-485. http://dx.doi.org/10.1111/j.1752-0606.2011.00226.x

Received: November 18, 2016

Accepted: November 18, 2016

Published: December 8, 2016 